Supporting Information for:

\title{
Stabilization of Urea for Recovery from Source-Separated Urine Using Electrochemically Synthesized Hydrogen Peroxide
}

Philip H. Arve, Sudeep C. Popat*

Department of Environmental Engineering and Earth Sciences, Clemson University, 342 Computer Ct, Anderson, SC 29525, USA

${ }^{*}$ Corresponding author

e-mail: spopat@clemson.edu

phone: (864) 656-5568

6 pages

0 tables

5 figures 


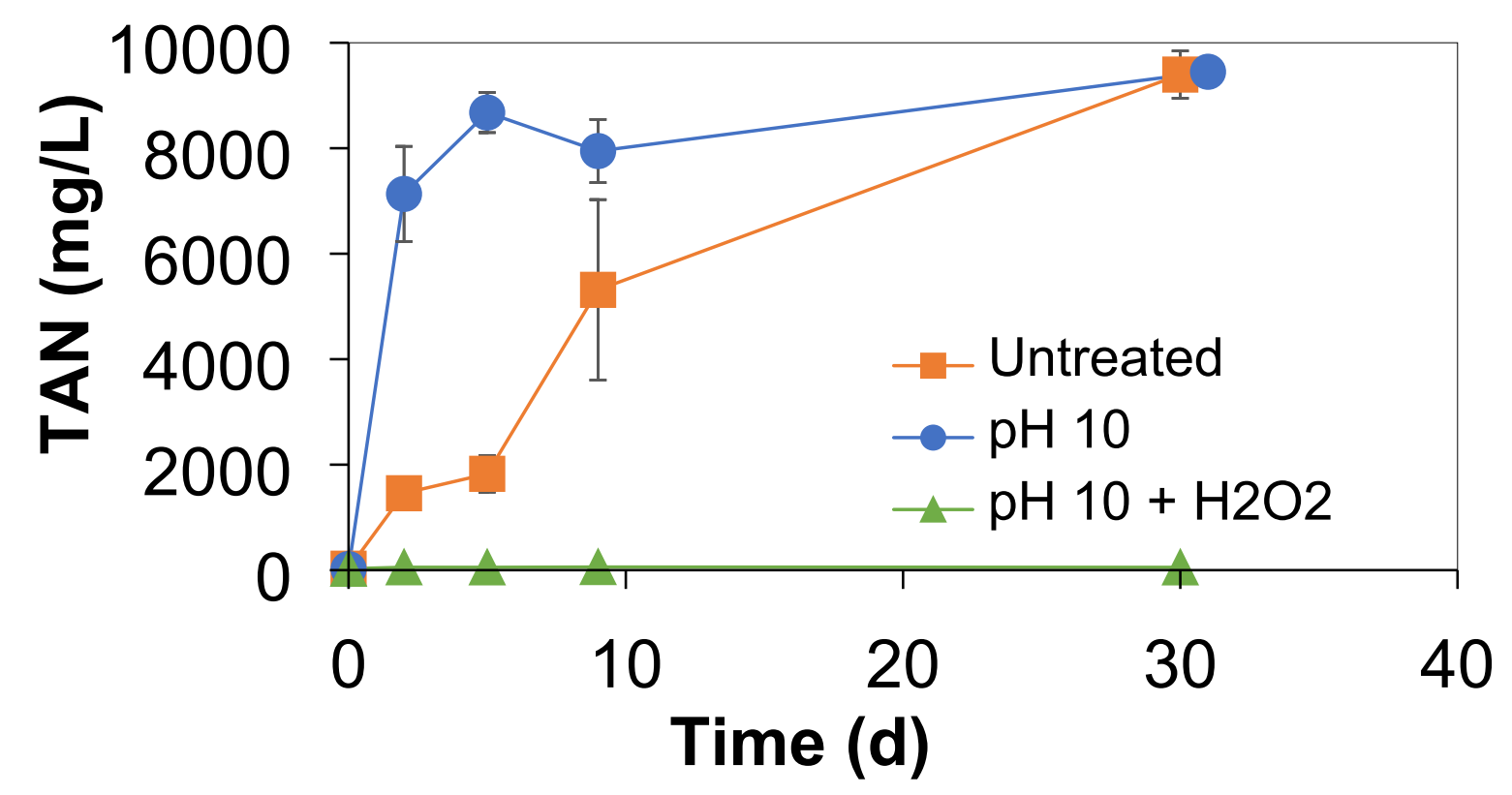

Figure S1. Effect of pH on urea hydrolysis in synthetic urine. Only urease was added to untreated samples. $\mathrm{pH} 10$ samples were adjusted with $1 \mathrm{M} \mathrm{NaOH}$ prior to the addition of urease. $\mathrm{pH} 10+\mathrm{H}_{2} \mathrm{O}_{2}$ samples were adjusted with $1 \mathrm{M} \mathrm{NaOH}$ and $\mathrm{H}_{2} \mathrm{O}_{2}$ was added from a $35 \% \mathrm{w} / \mathrm{w}$ stock solution to achieve $1 \mathrm{~g} / \mathrm{L} \mathrm{H}_{2} \mathrm{O}_{2}$ prior to the addition of urease. 

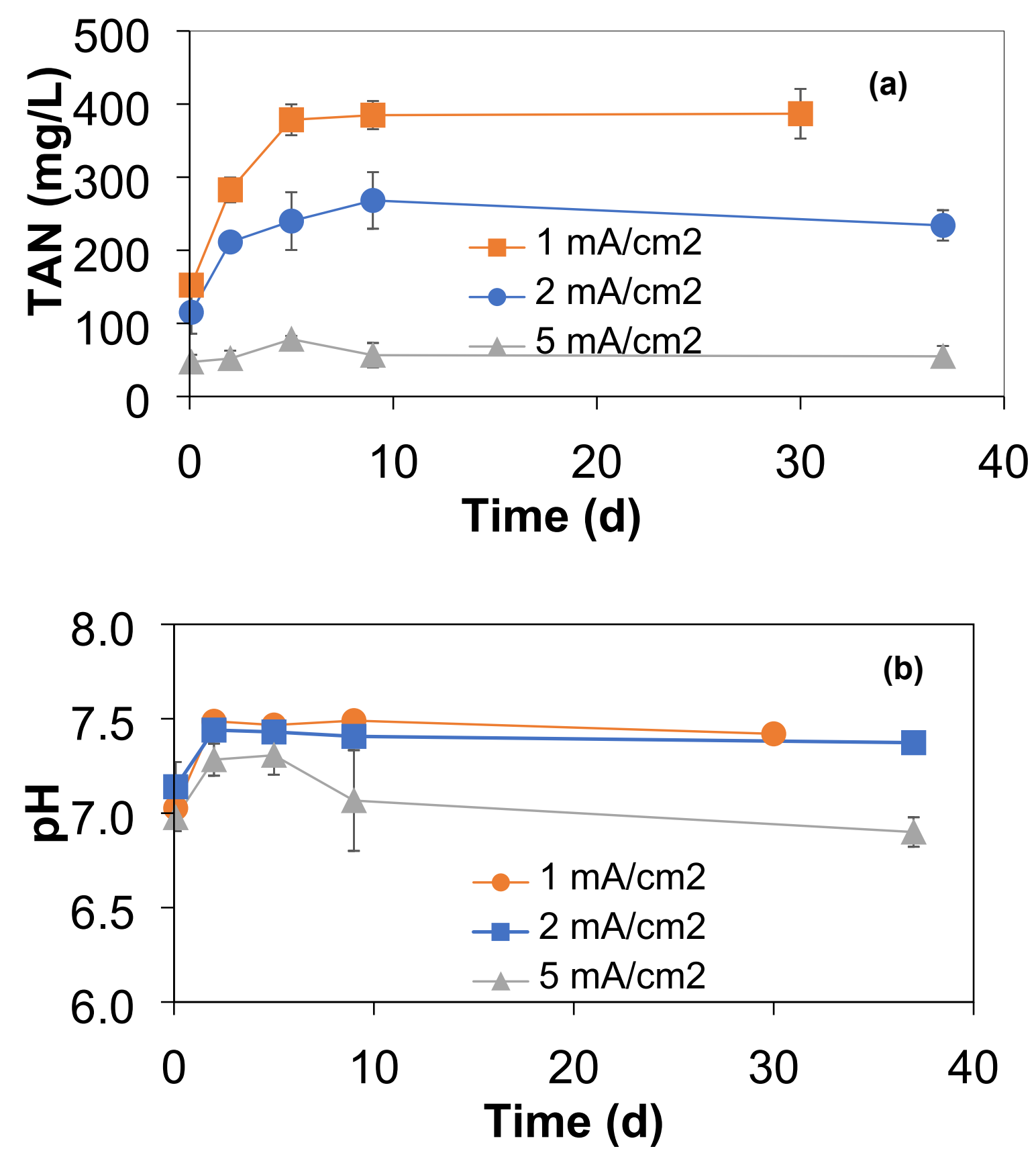

Figure S2. Effect of current density during treatment with electrochemically synthesized $\mathrm{H}_{2} \mathrm{O}_{2}$ on (a) TAN formation and (b) $\mathrm{pH}$ following $\mathrm{pH}$ adjustment to neutral. Error bars show standard deviation from three replicate experiments. 



Figure S3. Effect of treatment time with electrochemically synthesized $\mathrm{H}_{2} \mathrm{O}_{2}$ on (a) TAN formation and (b) $\mathrm{pH}$ following $\mathrm{pH}$ adjustment to neutral. Error bars show standard deviation from three replicate experiments. 

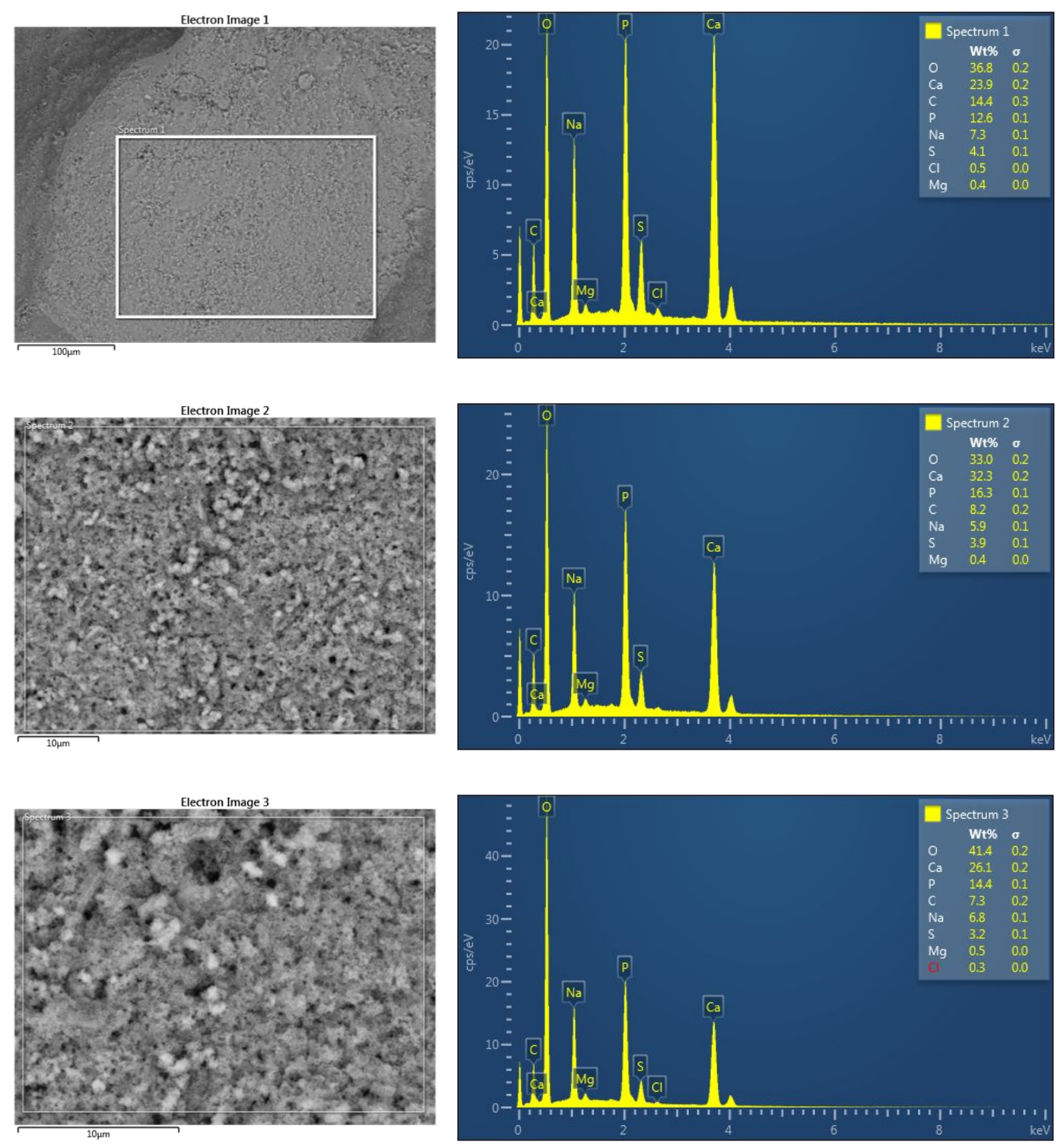

Figure S4. SEM-EDS analysis of solid precipitates from the cathode. Calcium, phosphorus, and oxygen were the most prevalent elements, followed by carbon, sodium, and sulfur. 


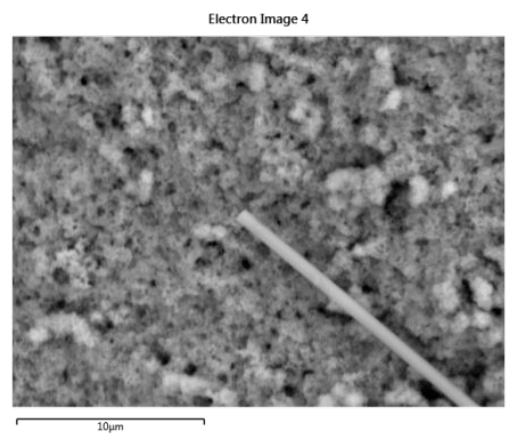

$\mathrm{O} K \alpha 1$

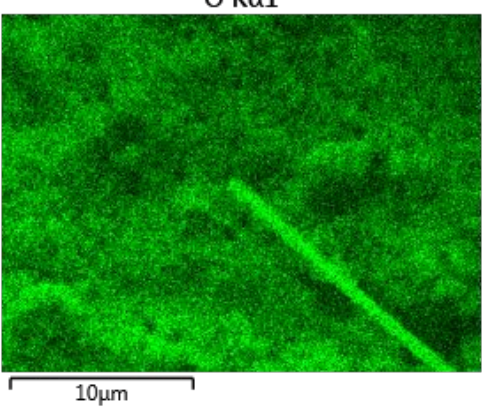

Na K $\alpha 12$

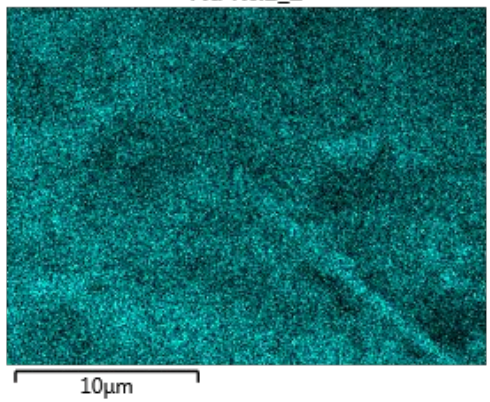

Si K $\alpha 1$

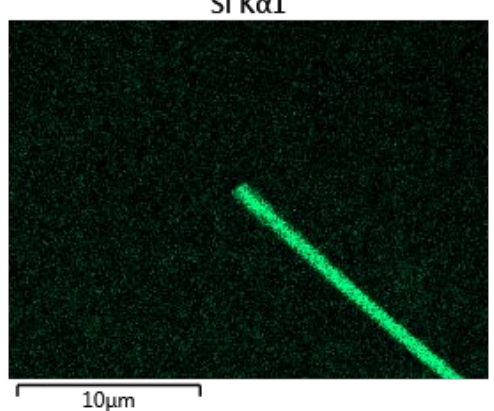

$\mathrm{P} K \alpha \mathbf{1}$

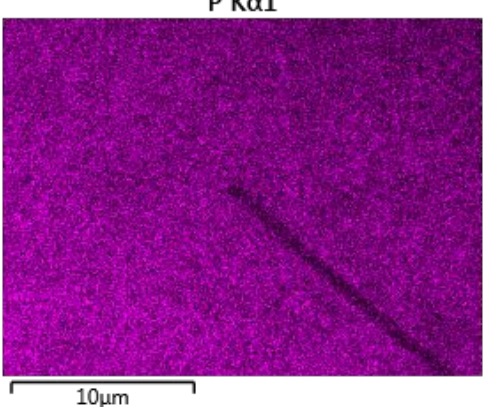

C Kal_2

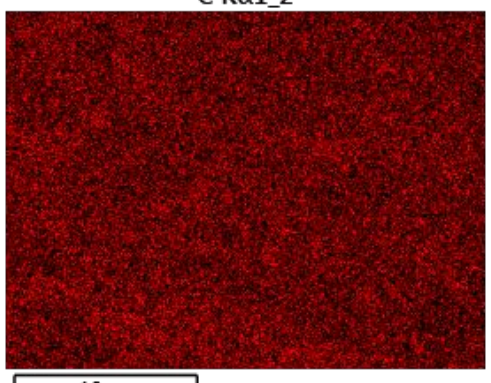

$10 \mu \mathrm{m}$

$\mathrm{Mg} \mathrm{K \alpha 1 \_ 2}$

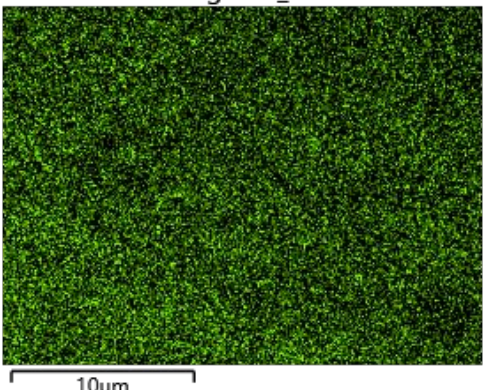

$\mathrm{Ca} \mathrm{K} \alpha 1$
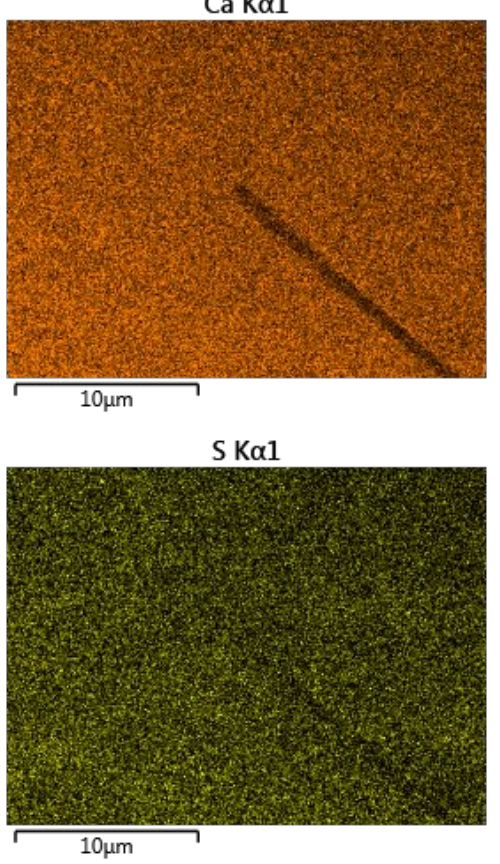

$\mathrm{Cl} \mathrm{K \alpha 1}$

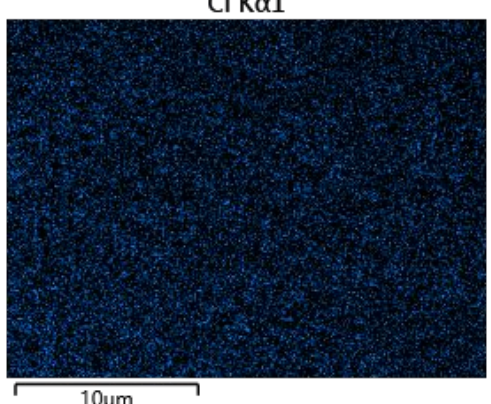

Figure S5. Element maps of solid precipitates from the cathode. No discernable crystal formations suggest these precipitates are homogenous. 
The average cost of electricity ${ }^{1}$ was used to determine the cost to stabilize urea with a current density of $20 \mathrm{~A} / \mathrm{m}^{2}$ for $1 \mathrm{~h}$. The cost to stabilize urea with in situ electrochemically produced hydrogen peroxide is calculated as follows:

$$
\frac{0.116 U S D^{1}}{k W h} \times \frac{1.88 \mathrm{kWh}}{\mathrm{m}^{3}} \times \frac{\mathrm{m}^{3}}{1000 \mathrm{~L}} \times \frac{1 \mathrm{~L}}{17.7 \mathrm{~g} \text { urea }} \times \frac{1000 \mathrm{~g} \text { urea }}{1 \mathrm{~kg} \text { urea }}=0.012 \mathrm{USD} / \mathrm{kg \text {urea }}
$$

This value of $\$ 0.012 / \mathrm{kg}$ was compared to the current overall production cost of urea. Using the 5-year average price of natural gas ${ }^{2}$ and the granular urea cash cost build-up calculator provided by Yara International $\mathrm{ASA}^{3}$, the average cost of urea production was calculated to be $\$ 0.109 / \mathrm{kg}$. While this number is nearly ten times greater than the cost to stabilize urea with in situ electrochemically produced hydrogen peroxide, costs associated with operation and maintenance of the electrochemical cell and transport and further refinement of the stabilized urine that would increase the price of urea recovery from urine are not included as they are beyond the scope of this study. Further refinement and optimization of the processes surrounding urea stabilization with electrochemically synthesized $\mathrm{H}_{2} \mathrm{O}_{2}$ may allow this technology to become economically feasible in relation to current industrial production of urea

\footnotetext{
${ }^{1}$ Average cost per kWh in United States for February 2021 for all sectors:

https://www.eia.gov/electricity/monthly/epm_table_grapher.php?t=epmt 5_6_a

${ }^{2}$ Henry Hub NG Spot Price - https://www.eia.gov/dnav/ng/hist/rngwhhdD.htm

${ }^{3}$ Yara Granular urea cash cost build-up:

https://www.yara.com/investor-relations/analyst-information/calculators/ammonia-and-urea-cash-cost/
} 